\title{
Nanostructured $\mathrm{Mn}$-doped $\mathrm{CeO}_{2}$ thin films with enhanced electrochemical properties for pseudocapacitive applications
}

\author{
Iheke Micheal Nwachukwu ${ }^{\mathrm{a}}$, Assumpta Chinwe Nwanya ${ }^{\mathrm{a}, \mathrm{b}, *}$, Rose Osuji ${ }^{\mathrm{a}, \mathrm{c}, \mathrm{d}}$, \\ Fabian I. Ezema ${ }^{\mathrm{a}, \mathrm{c}, \mathrm{d}}$ \\ a Department of Physics and Astronomy, University of Nigeria, Nsukka, Nigeria \\ ${ }^{\mathrm{b}}$ SensorLab, (University of the Western Cape Sensor Laboratories), 4th Floor Chemical Sciences Building, Robert Sobukwe Road, Bellville 7535, Cape Town, South \\ Africa \\ ' UNESCO-UNISA Africa Chair in Nanosciences-Nanotechnology, College of Graduate Studies, University of South Africa, Muckleneuk Ridge, South Africa \\ ${ }^{\mathrm{d}}$ Nanosciences African Network (NANOAFNET), iThemba LABS-National Research Foundation, 1 Old Faure road, Somerset West 7129, PO Box 722, Somerset West, \\ South Africa
}

\section{A R T I C L E I N F O}

\section{Article history:}

Received 17 June 2021

Received in revised form 14 July 2021

Accepted 15 July 2021

Available online 17 July 2021

\section{Keywords:}

Cerium oxide

Manganese

Pseudocapacitors

SILAR

Specific capacitance

\begin{abstract}
A B S T R A C T
Cerium oxides with variable oxidation states, high interfacial charge transfer rate have demonstrated to be a potential pseudocapacitive material. In this paper, we present the structural and electrochemical properties of undoped and $\mathrm{Mn}$-doped $\mathrm{CeO}_{2}$ synthesized using successive ionic layer adsorption and reaction(SILAR) method. The structural results as obtained from x-ray diffraction (XRD) confirmed the cubic fluorite structure of $\mathrm{CeO}_{2}$ which was unaltered despite the doping concentration. However, a tensile strain of $\sim 2.3 \%$ was observed due to ionic radii difference. The topography showed a porous network of nanograins, accounting for strong redox interfacial charge transfer. A specific capacitance of $690 \mathrm{Fg}^{-1}$ was obtained for $5 \mathrm{wt} \% \mathrm{Mn}$-doped $\mathrm{CeO}_{2}$, from cyclic voltammetry curve at a scan rate of $10 \mathrm{mV} / \mathrm{s}$. This value is considerably higher than what was obtained for the undoped ceria, indicating that doping with Mn improved the electrochemical performance of the ceria films.
\end{abstract}

(c) 2021 Elsevier B.V. All rights reserved.

\section{Introduction}

Reducing fossil fuel consumption and greenhouse emissions has become a global objective that is imperative for the world's sustainability. Recently, many researchers have given much attention to energy storage systems such as capacitors, supercapacitors, batteries and fuel cells since alternative renewable energy resources that are being advocated for are not always available. Hence, it is imperative to store energy from these renewable energy resources to be used when they are not available as well as for off grid applications. Among energy storage systems, electrochemical capacitors (ECs) otherwise called supercapacitors have received much interest as they are characterized by higher specific power of several orders of magnitude compared to most batteries and fuel cells [1,2]. Electrode materials for ECs include carbon-based materials (graphene, CNT etc), metal oxides $\left(\mathrm{CeO}_{2}, \mathrm{RuO}_{2}, \mathrm{Fe}_{2} \mathrm{O}_{3}\right.$ etc.) and conducting polymers (polyaniline, polypyrrole, polythiophene etc.). Development of new

\footnotetext{
* Corresponding author at: Department of Physics and Astronomy, University of Nigeria, Nsukka, Nigeria

E-mail address: chinwe.nwanya@unn.edu.ng (A.C. Nwanya).
}

electrochemical supercapacitor electrode material has been recently deployed to overcome the challenges of low energy density. This has been achieved by hybridizing the electrode materials through the addition of electrochemically active materials to a carbon-particlebased energy storage (ES) electrode layer or totally replacing the carbon materials with electrochemically active materials [2].

In the fabrication of supercapacitors and improvement of electrochemical performance of pseudocapacitors, materials with high porosity and large surface areas are highly suitable [3,4]. Despite the intrinsic properties of ruthenium and iridium oxides, its applications are greatly affected by high cost, scarcity and high toxicity [5,6]. Due to these inadequacies, exploration of electrode materials such as $\mathrm{CeO}_{2}, \mathrm{MnO}_{2}, \mathrm{NiO}, \mathrm{Co}_{3} \mathrm{O}_{4}, \mathrm{Fe}_{2} \mathrm{O}_{3}$ amongst others have gained much attention by researchers [7-9]. However, $\mathrm{CeO}_{2}$ has been proven convenient, conducive and promising electrode material for supercapacitors due to its low toxicity, abundance and outstanding redox properties. Because of its redox property, it is used as a promising and convenient electrode material for supercapacitors [10].

Various $\mathrm{CeO}_{2}$ composites, such as graphene- $\mathrm{CeO}_{2}$ [11,12], $\mathrm{GO}-\mathrm{CeO}_{2}$ [13], $\mathrm{SnO}_{2}-\mathrm{CeO}_{2}$ [14], $\mathrm{CNTs@CeO} 2$ hollow nanotubes [15] and $\mathrm{rGO}-\mathrm{CeO}_{2}$ [16], with specific capacitances that is higher than that of the undoped 
$\mathrm{CeO}_{2}$ have been successfully synthesized and reported. Hua et al. [17], synthesized ceria/ZnO composite using ultrasonic assisted successive ionic layer adsorption and reaction (SILAR) method and the films were used in catalysis. Moreover, a specific capacitance of $1027.8 \mathrm{Fg}^{-1}$ has been reported by Cui et al. using hydrothermal approach to synthesize multilayered $\mathrm{CeO}_{2}$ such as $\mathrm{NiO} / \mathrm{MnO}_{2} / \mathrm{CeO}_{2}$ hybrid nanoflake arrays [18]. However, this synthesis involves a laborious process with several calcination steps and the hydrothermal method is prone to wide dimension standard deviation making it difficult to precisely control the final size and morphology of the films. Although most papers reported composites and multilayered materials, a recent work showed that only the nanostructured $\mathrm{CeO}_{2}$ presents high capacitance of $927 \mathrm{Fg}^{-1}$ at $2 \mathrm{Ag}^{-1}$ current density [19]. Doping of $\mathrm{CeO}_{2}$ is also a promising strategy to improve the electrochemical performance of this material since the specific capacitance enhancement and cyclic stability of $\mathrm{CeO}_{2}$ nanostructures is based on the availability of valence $4 \mathrm{f}$ electrons [20]. In this way, some works have been carried out by doping the $\mathrm{CeO}_{2}$ with $\mathrm{Mn}$ [21], noble metals like Ag and transition metals like La, Mn, Co or Ni [20] and $\mathrm{Fe}$ [22]. It was demonstrated that specific capacitance and electrochemical stability were enhanced with transition metal doping in particular with Mn dopant [14]. However more work is needed to optimize the dopant percentage and understand the physical processes involved as well as the development of simple, low-coast and highly reproducible synthesis methods. Therefore, an easily achievable synthesis approach that supports large surface area fabrication on different types substrates is successive ionic layer adsorption and reaction (SILAR) method which operates with the principle of the immersion of substrates into separately placed cationic and anionic precursors. SILAR method is one of the modified chemical methods for depositing uniform and large area thin films. In addition, precipitate formation in the solution is minimized. Furthermore, the deposition rate and the thickness of the films can easily be controlled over a given range of cycles and local over heating which may be detrimental to the deposited films can be avoided. Few reports have been published on the synthesis of $\mathrm{CeO}_{2}$ using SILAR method [17]. However, to the best of the knowledge of the authors, no report of Mndoped $\mathrm{CeO}_{2}$ synthesized using the SILAR method and tailored to energy storage application has been reported. Therefore, this work is among the first attempt towards the use of Mn doped cerium oxide synthesized via SILAR method for pseudocapacitor application.

\section{Materials and methods}

We used analytical grade of chemicals which include cerium nitrate hexahydrate $\left(\mathrm{Ce}\left(\mathrm{NO}_{3}\right)_{3} \cdot 6 \mathrm{H}_{2} \mathrm{O}\right)$, manganese acetate $\left(\mathrm{CH}_{3}\right.$. $\left.(\mathrm{COO})_{2} \mathrm{Mn} 0.4 \mathrm{H}_{2} \mathrm{O}\right)$ and hydrogen peroxide $\left(\mathrm{H}_{2} \mathrm{O}_{2}\right)$ and all were obtained from Sigma-Aldrich company. They were used without further purification.

\subsection{Preparation of undoped $\mathrm{CeO}_{2}$ and $\mathrm{Mn}$-doped $\mathrm{CeO}_{2}$ thin films}

The immersion of substrates into separately placed anion and cation precursor solutions employed in this experiment obeys the principle of successive ionic layer adsorption and reaction technique. As illustrated in Fig. 1, four beakers were used for the deposition of undoped and $\mathrm{Mn}$-doped $\mathrm{CeO}_{2}$ thin films on substrates. Substrate pretreatment procedures have been described elsewhere [23].

$\mathrm{Mn}$-doped $\mathrm{CeO}_{2}$ thin films were prepared using $\left(\mathrm{Ce}\left(\mathrm{NO}_{3}\right)_{3} \cdot 6 \mathrm{H}_{2} \mathrm{O}\right)$ and $\mathrm{CH}_{3}$. $(\mathrm{COO})_{2} \mathrm{Mn} 0.4 \mathrm{H}_{2} \mathrm{O}$ (for various concentration of $\mathrm{Mn}^{4+}=1,3$, and $5 \mathrm{wt} \%$ ). $2.0 \mathrm{ml}$ of $\mathrm{H}_{2} \mathrm{O}_{2}$ mixed with $100 \mathrm{ml}$ of distilled water was used as the complexing agent and the anionic precursor. Beakers (a) and (c) containing respectively the cationic and anionic precursors were heated to $85^{\circ} \mathrm{C}$ while those containing distilled water (i.e. beakers $b$ and $d$ ) were kept at room temperature. Duration for immersion in cationic and anionic beakers are $20 \mathrm{~s}$ each while the time for rinsing in the beaker containing distilled water was $5 \mathrm{~s}$. In this case, a total of 20 cycles was carried out. Varying the number of

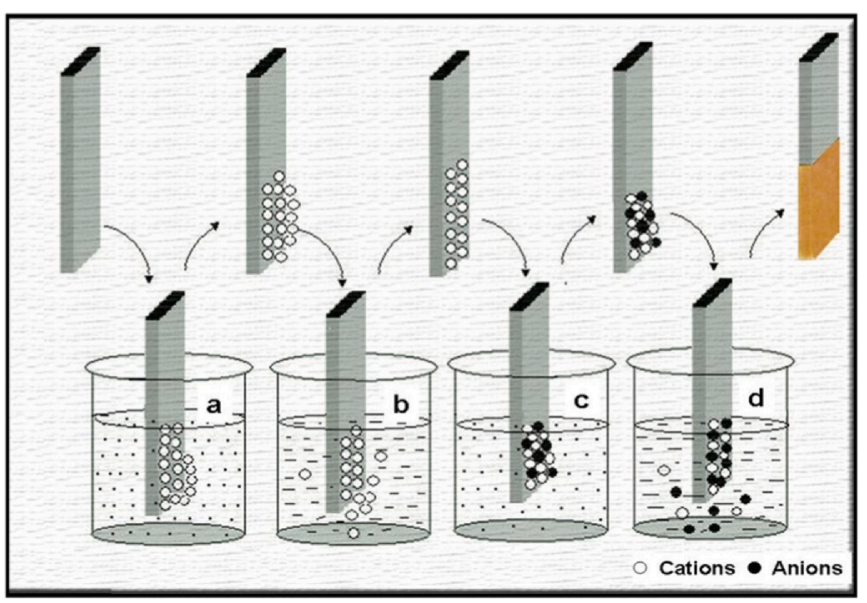

Fig. 1. Schematic representation of SILAR deposition technique.

cycles helps to control the thickness of the deposited films. Similarly, for the deposition of $\mathrm{CeO}_{2}$, the process was repeated without the addition of $\mathrm{Mn}^{4+}$. The films were annealed at $600{ }^{\circ} \mathrm{C}$ for $6 \mathrm{~h}$ in order to improve the crystal sizes.

\subsection{Characterization techniques}

Atomic force microscope (AFM) operating in tapping mode was used in measuring the topographical structure of the SILAR deposited films. The structure of undoped $\mathrm{CeO}_{2}$ and $\mathrm{Mn}$-doped $\mathrm{CeO}_{2}$ were studied on $\mathrm{x}$ ray diffractometer (Rigaku SmartLab diffractometer) with $\mathrm{Cu}-\mathrm{K} \alpha$ radiation $(\lambda=1.540593 \AA)$. XPS measurements were used to determine the binding energies of $\mathrm{CeO}_{2}, \mathrm{Mn}: \mathrm{CeO}_{2}$, $\mathrm{Ce} 3 \mathrm{~d}, \mathrm{Mn} 2 \mathrm{p}$ and $\mathrm{O}$ 1s from Kratos AXIS Nova Spectrometer (Kratos Analytical Ltd., Canada) using the Al-Ko $(1486.74 \mathrm{eV}$ ) operating at $250 \mathrm{~W}$ (beam power). Optical studies were done via transmittance spectra which was recorded within the wavelength range of 300-1100 nm using Beckman Coulter DU 720 UV-VisNIR spectrophotometer with untreated glass as reference. The electrochemical properties of the films were studied using a potentiostat (VersaSTAT MC, Princeton Applied Research) workstation, in a threeelectrode set-up. The $0.1 \mathrm{M} \mathrm{KOH}$ aqueous solution was used as electrolyte while graphite rod and $\mathrm{Ag} / \mathrm{AgCl}$ was used as counter electrode and reference electrode respectively.

\section{Results and discussion}

\subsection{X-ray diffraction (XRD) analysis}

The x-ray diffraction pattern of $\mathrm{CeO}_{2}$ and $\mathrm{Mn}$-doped $\mathrm{CeO}_{2}$ thin films are depicted in Fig. 2. From the patterns, it was evident that ceria based thin films crystallized out in a cubic structure which are indexed to JCPDS No. 34-0394. The Bragg reflections show the fluorite structure of $\mathrm{CeO}_{2}$ is in strong agreement with those reported in the literature [24-26]. In the Mn-doped samples, there was no indication of additional peaks ascribed to impurities, such as $\mathrm{MnO}_{2}$. A closer inspection of the most intense peak at $2 \theta=28.5^{\circ}$ showed slight peak shift towards the lower $2 \theta$ angle with a slight increase in the full width at half maximum (FWHM). This indicates the instability and probable structural adjustment in the cubic lattice. Considering the ionic radii of $\mathrm{Ce}^{4+}(0.97 \AA$, coordination number, $\mathrm{CN}=8)$ and $\mathrm{Mn}^{4+}(0.96 \AA)$ as the substituent, the effect of cationic disordering is therefore noted. By using Scherrer, Williamson and Hall equation [27]:

$\beta_{2 \theta}=(\mathrm{k} \lambda / \mathrm{D} \cos \theta)+4 \varepsilon \tan \theta$

(where $\beta_{2 \theta}=$ is the line broadening at half the maximum intensity, $\mathrm{D}=$ crystalline size, $\mathrm{k}=$ shape factor, $\lambda=$ wavelength of radiation, $\theta=$ is 

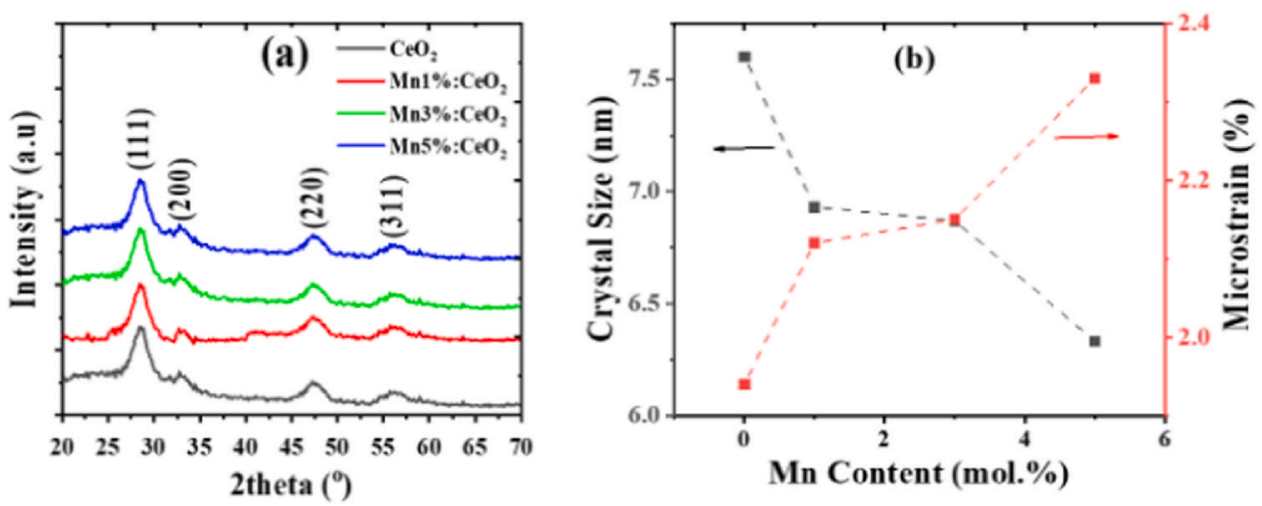

Fig. 2. (a) XRD pattern of as deposited samples of undoped $\mathrm{CeO}_{2}$ and $\mathrm{Mn}$-doped $\mathrm{CeO}_{2}$ (b) Variation of the microstrain versus $\mathrm{Mn}$ content.

the bragg angle and $\varepsilon=$ is the microstain in radians, which is the ratio of peak width to peak position), the crystal size and microstrain of the films were estimated. The obtained results show that crystal size decreases by increased concentration of the dopant whereas the tensile strain increases culminating to $2.3 \%$ for $5 \mathrm{wt} \%$ of $\mathrm{Mn}$ (see Fig. 2b). This can be explained by slight ionic radii variance between Ce and Mn. However, it is worth noting that the fluorite structure maintained almost its unit cell volume despite the strain.

\subsection{X-ray photoelectron spectroscopy (XPS) analysis}

XPS was used in quantifying the oxidation states and identifying the differences in the core-line spectra of undoped and Mn-doped $\mathrm{CeO}_{2}$. Fig. 3a shows the spectrum of $\mathrm{CeO}_{2}$ and $\mathrm{Mn}$-doped $\mathrm{CeO}_{2}$ while Fig. 3(b-d) respectively show the XPS spectra of Mn 2p, 01 s
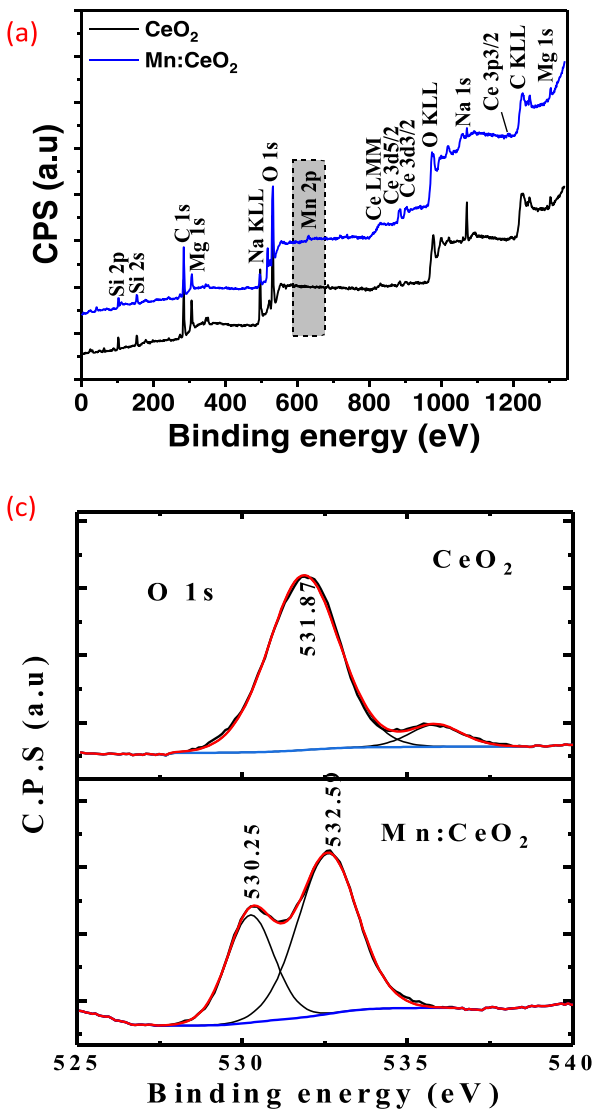

and $\mathrm{Ce} 3 \mathrm{~d}$. In the $\mathrm{O} 1 \mathrm{~s}$ spectra, the peak at $531.87 \mathrm{eV}$ likely corresponds to the lattice oxygen while the deconvoluted peak at $530.25 \mathrm{eV}$ in the $\mathrm{Mn}$ doped $\mathrm{CeO}_{2}$ may be due to oxygen vacancy in the material arising from mismatch in ionic radii of $\mathrm{Ce}^{4+}$ and $\mathrm{Mn}^{2+}$. The peaks at $640.75 \mathrm{eV}$ and $642.23 \mathrm{eV}$ in the Mn 2p XPS spectra (Fig. 3b) demonstrate the presence of $\mathrm{Mn}^{4+}$. In Fig. $3 \mathrm{~d}$, the highest binding energy peaks located at $885.02 \mathrm{eV}$ and $881.98 \mathrm{eV}$ are the result of $\mathrm{Ce} 3 \mathrm{~d} 5 / 2$ while the lowest binding energy states are at $881.19 \mathrm{eV}$ and $885.85 \mathrm{eV}$. Mn 2p peak has significantly split spinorbit components as well as asymmetric shape for metal. However, the following observations were made: (i) the presence of $\mathrm{Ce}^{3+}$ was not noticed and (ii) the dopant ( $\mathrm{Mn}$ ) has no effect on the valence state of Ce.

To show the presence of oxygen in the sample, the $01 \mathrm{~s}$ spectrum in figure $3 \mathrm{c}$ has its peak at $531.87 \mathrm{eV}$. This is due to the effect of $\mathrm{O}^{2-}$.
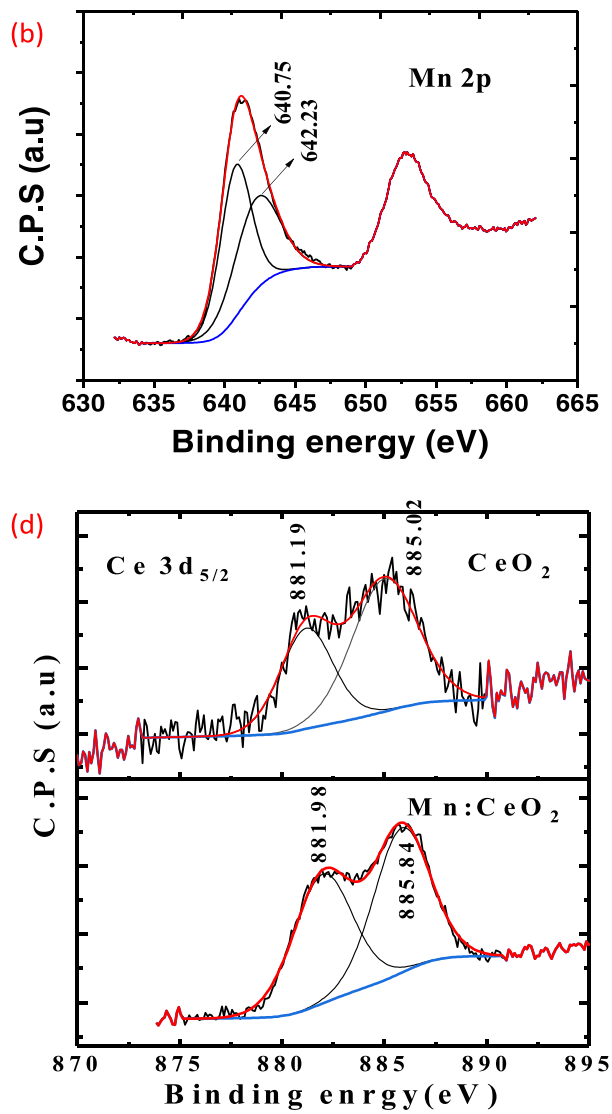

Fig. 3. The XP spectra plots. (a) survey spectra of $\mathrm{CeO}_{2}$ and $\mathrm{Mn}$-doped $\mathrm{CeO}_{2}$, (b) $\mathrm{Mn} 2 \mathrm{p}$ spectra, (c) $\mathrm{O} 1 \mathrm{~s}$ spectra, (d) $\mathrm{Ce} 3 \mathrm{~d}$ spectra. 

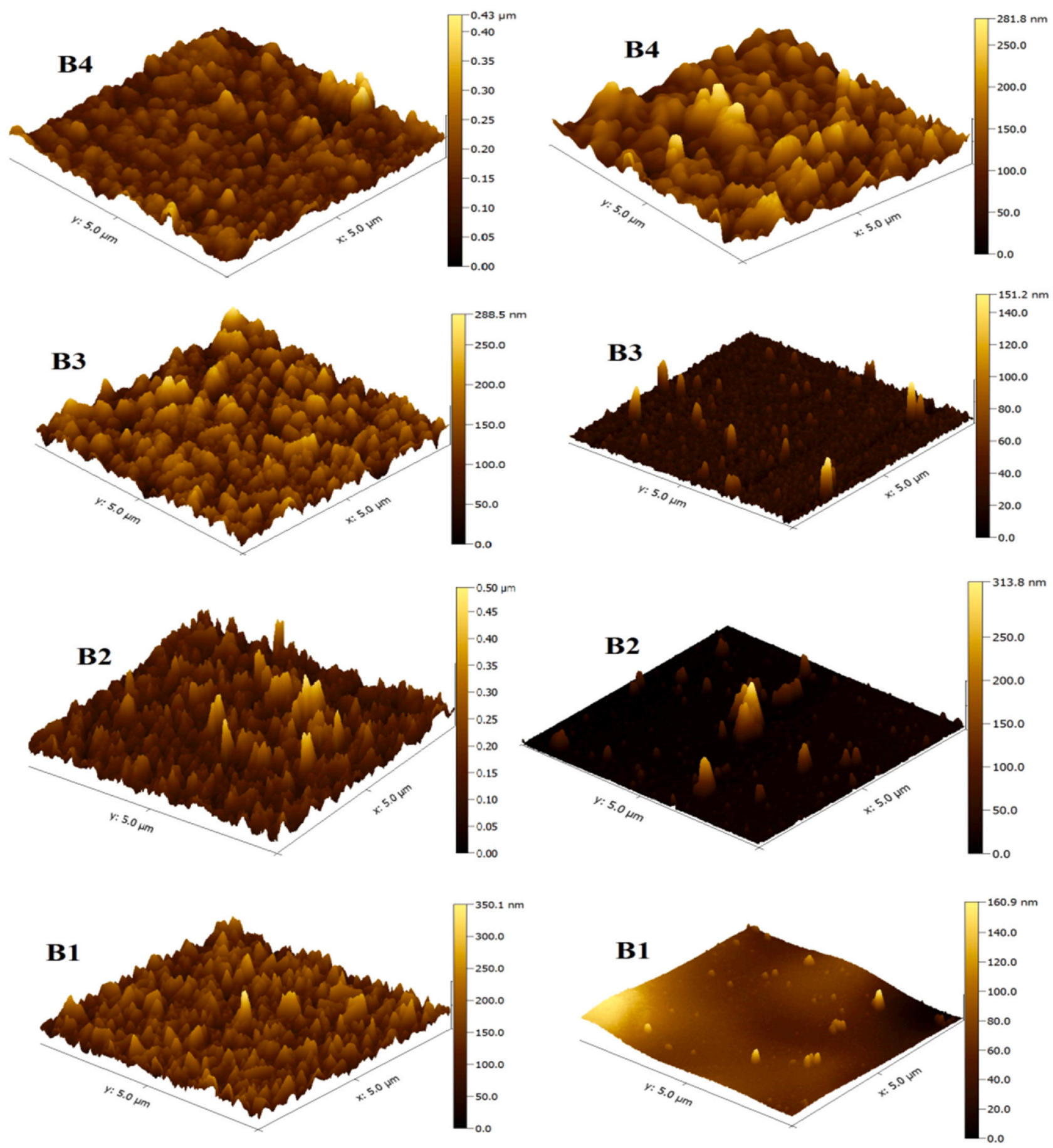

As-Deposited Samples

Annealed Samples

Fig. 4. AFM images showing the roughness of as-deposited and annealed films. (B1, B2, B3 and $\mathrm{B} 4$ is the undoped $\mathrm{CeO}_{2}, 1 \mathrm{wt} \%, 3 \mathrm{wt} \%$ and $5 \mathrm{wt} \% \mathrm{Mn}$-doped $\mathrm{CeO} 2$ respectively).

The interaction of the $\mathrm{O}-\mathrm{Mn}$ and $\mathrm{O}-\mathrm{Ce}$ bonds could be attributed to the presence of $\mathrm{Mn}: \mathrm{CeO}_{2}$ which was detected at $532.59 \mathrm{eV}$ in the $\mathrm{O}$ $1 \mathrm{~s}$ peak from the lattice oxygen. This is in agreement with the report of Eric et al. [28].

\subsection{Atomic force microscopy (AFM): surface topography and roughness}

AFM was used to determine the roughness and surface topography of the deposited films. Fig. 4 displays the AFM images of SILAR deposited undoped and $\mathrm{Mn}$-doped $\mathrm{CeO}_{2}$ thin films. The undoped and $\mathrm{Mn}$-doped $\mathrm{CeO}_{2}$ thin films are similar in texture. All the films were crack-free and dense on the surface. Despite the dense nature of the grains, the mean heights are in the range of 200-250 nm for the unannealed films. All the annealed samples appear smoother and more homogenous compared to unannealed samples. Surface roughness analysis as presented in Table 1, show a small increase in roughness as Mn content increases in the annealed films, while no trend was noted in the as-deposited films. Hence, the root mean square value of roughness are $51.8 \mathrm{~nm}$ and $26.0 \mathrm{~nm}$ respectively for annealed and unannealed $5 \mathrm{wt} \% \mathrm{Mn}$-doped $\mathrm{CeO}_{2}$. The 
Table 1

Roughness of undoped and $\mathrm{Mn}$-doped $\mathrm{CeO}_{2}$ films. (The presented values are Rq values in $\mathrm{nm}$, of $2 \mu \mathrm{m} \times 2 \mu \mathrm{m}$ square areas).

\begin{tabular}{|c|c|c|c|c|}
\hline Sample & $\mathrm{CeO}_{2}$ - Undoped & $\mathrm{CeO}_{2}-1 \mathrm{wt} \% \mathrm{Mn}$-doped & $\mathrm{CeO}_{2}-3 \mathrm{wt} \% \mathrm{Mn}$-doped & $\mathrm{CeO}_{2}-5$ wt\% Mn-doped \\
\hline Roughness (nm) - As-deposited & 34.7 & 44.9 & 38.4 & 41.8 \\
\hline Roughness (nm) - Annealed & 3.45 & 6.11 & 6.46 & 26.0 \\
\hline
\end{tabular}

Table 2

Grain size of the undoped and Mn-doped $\mathrm{CeO}_{2}$ films. (Values are the diameter of a circle of equivalent area).

\begin{tabular}{|c|c|c|c|c|}
\hline Sample label & $\mathrm{CeO}_{2}$ - Undoped & $\mathrm{CeO}_{2}-1 \mathrm{wt} \% \mathrm{Mn}$-doped & $\mathrm{CeO}_{2}-3 \mathrm{wt} \% \mathrm{Mn}$-doped & $\mathrm{CeO}_{2}-5 \mathrm{wt} \% \mathrm{Mn}$-doped \\
\hline Grain size (nm) - As deposited & 114.52 & 48.14 & 67.42 & 61.08 \\
\hline Grain size (nm) - Annealed & 60.87 & 28.10 & 48.93 & 63.03 \\
\hline
\end{tabular}

$5 \mathrm{wt} \%$ Mn-doped film was considerably rougher than the lower content films. In the same vein, grain size analysis as shown in Table 2 presents the estimation of the grain sizes of the synthesized thin films.

In general, the grain size estimation suggests smaller grains upon annealing of the films, with the exception of the 5\% Mn-doped film. The non-linearity in the grain size after annealing especially at $5 \%$ dopant concentration could be attributed to the inability of the dopant to form a ternary compound of high unit cell size with the host lattice at this concentration. The annealed and doped $\mathrm{CeO}_{2}$ films showed an increase in the grain size as doping concentration increased from $1 \%$ to $5 \%$. The reduction in the grain size with annealing could be attributed to the crystallization of the films, which lead to reduction in defects and increase in perfection with concomitant reduction in the grain size. On the other hand, the increase in the grain size of the annealed and Mn doped films suggests that the incorporation of $\mathrm{Mn}$ ion enhances the growth of the $\mathrm{CeO}_{2}$ film.

\subsection{Optical absorption studies}

Fig. 5 shows that the absorption edge of the nanostructured $\mathrm{CeO}_{2}$ shifted into the visible region due to the charge transfer transition of ions from $2 \mathrm{p}\left(\mathrm{O}^{2-}\right)$ to $4 \mathrm{f}\left(\mathrm{Ce}^{4+}\right)$ orbitals $[29,30]$. Hence, the spectral profiles show that the $4 \mathrm{f}^{1}-5 \mathrm{~d}^{1}$ transition of $\mathrm{Ce}^{3+}$ project with charge transfer transition of $\mathrm{Ce}^{4+}[31]$. The optical band gap $\left(E_{\mathrm{g}}\right)$ was evaluated from Eq. (2):

$E_{\mathrm{g}}=1240 / \lambda$

where $\lambda$ is the absorption edge wavelength. From Table 3 , the value of $E_{\mathrm{g}}$ for undoped $\mathrm{CeO}_{2}$ is in agreement with the reports in the

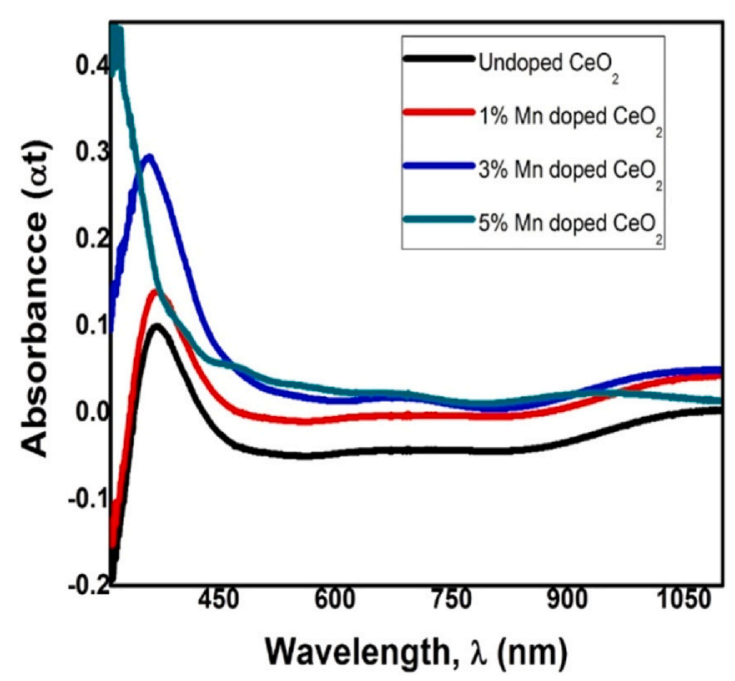

Fig. 5. Optical absorption spectra of the nanostructured undoped and $\mathrm{Mn}$ doped $\mathrm{CeO}_{2}$ thin films.
Table 3

The energy band gap of undoped and $\mathrm{Mn}$-doped $\mathrm{CeO}_{2}$ of various concentrations.

\begin{tabular}{lllll}
\hline & Undoped $\mathrm{CeO}_{2}$ & \multicolumn{4}{l}{$\mathrm{Mn}$-doped $\mathrm{CeO}_{2}$ (wt\%) } \\
\cline { 3 - 5 } & & 1 & 3 & 5 \\
\hline Unannealed $(\mathbf{e V})$ & 2.38 & 2.75 & 3.00 & 3.19 \\
Annealed $(\mathbf{e V})$ & 2.50 & 2.90 & 2.85 & 2.55 \\
\hline
\end{tabular}

literature [30-32]. Comparatively, many authors have also reported this similar trend of the band gap for $\mathrm{Mn}$ - and $\mathrm{Ni}$-doped $\mathrm{CeO}_{2}$ $[33,34]$. The extensive structural changes observed and reduction in the band gap of $\mathrm{CeO}_{2}$ as $\mathrm{Mn}$ percentage increases could be ascribed to the incorporation of interstitial dopant [34]. The decrease in $E_{g}$ of annealed $3 \mathrm{wt} \%$ and $5 \mathrm{wt} \%$ samples can be as a result of the improvement in morphology and crystallinity of the samples.The fusion of Mn ions could be assigned to the presence of the observed peak shift which must be due to oxygen vacancies or impurities [33].

Consequently, presence of oxygen vacancies and impurities affects the band gap and also occurred in the formation of transition states. However, narrowing of band gap exhibited by Mn-doped $\mathrm{CeO}_{2}$ has potential applications in photocatalytic or photovoltaic systems [35].

\subsection{Electrochemical studies}

\subsubsection{Cyclic voltammetry (CV)}

Fig. 6 shows the $\mathrm{CV}$ curves of undoped and $\mathrm{Mn}$-doped $\mathrm{CeO}_{2}$ analyzed at different scan rates. The presence of strong redox peaks at each curve is clear evidence that capacitance characteristics are in coordinate with Faradaic reactions. The peaks are due to $\mathrm{Ce}^{3+} \leftrightarrow \mathrm{Ce}^{4+}$ redox processes. Some responses of $\mathrm{CeO}_{2}$ and $\mathrm{Mn}$-doped $\mathrm{CeO}_{2}$ that show pseudocapacitive behavior are:

(i) the presence of noticeable peaks especially at lower scan rates,

(ii) the variation in wt\%, produces different shapes of CV curves for different samples and

(iii) the increase in scan rate resulted in the shifts in positive and negative directions of the potential of the cathodic and anodic peaks respectively.

The specific capacitance of $\mathrm{CeO}_{2}$ and $\mathrm{Mn}$-doped $\mathrm{CeO}_{2}$ samples can be estimated by using Eq. (3):

$C_{s}=\frac{\int I d t}{m \frac{d V}{d t}}$

where $m=$ the mass of deposit, $(d V / d t)=$ the scan rate, $\int l d t=$ the area under the CV curve and $C_{s}=$ the specific capacitance (F/g) [36-39]. The specific capacitance values at potential scan rates of 10, 20 and $100 \mathrm{mV} / \mathrm{s}$ were observed to be $\sim 410-275 \mathrm{~F} / \mathrm{g}$ for undoped $\mathrm{CeO}_{2}$ while for the 1,3 and $5 \mathrm{wt} \% \mathrm{Mn}$ films, the values are $486-280 \mathrm{~F} / \mathrm{g}$, 509-297 F/g and 690-382 F/g, respectively. At higher scan rate, the specific capacitance value decreases because the ions do not have 

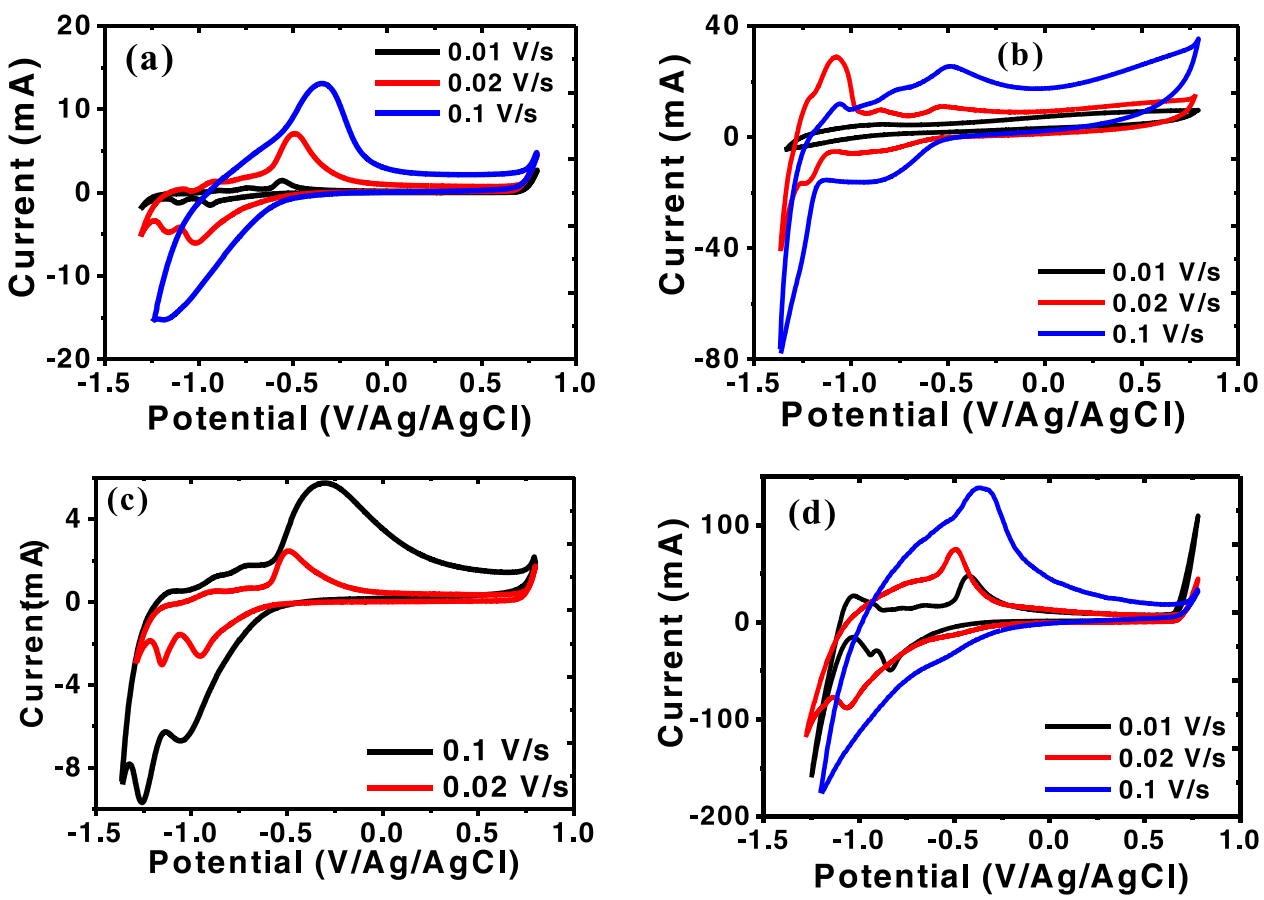

Fig. 6. $\mathrm{CV}$ curves at different scan rates of (a) Undoped $\mathrm{CeO}_{2}$ (b) 1 wt\% $\mathrm{Mn}$-doped $\mathrm{CeO}_{2}$ (c) 3 wt\% $\mathrm{Mn}$-doped $\mathrm{CeO}_{2}$ (d) 5 wt $\% \mathrm{Mn}$-doped $\mathrm{CeO}_{2}$.

Table 4

Specific capacitances from some $\mathrm{CeO}_{2}$ composites at different synthesis techniques and scan rates.

\begin{tabular}{|c|c|c|c|c|}
\hline Electrode & Synthesis Techniques & Specific Capacitance $\left(\mathrm{Fg}^{-1}\right)$ & Scan rate $\left(\mathrm{mVs}^{-1}\right)$ & Ref. \\
\hline $\mathrm{CeO}_{2} /$ Graphene & Solid State Route & 652 & 5 & [11] \\
\hline $\mathrm{CeO}_{2} /$ Graphene & Solid State Route & 110 & 10 & [12] \\
\hline $\mathrm{CeO}_{2} / \mathrm{rGO}$ & Oil bath Method & 243 & 20 & [13] \\
\hline $\mathrm{rGO}-\mathrm{CeO}_{2}$ & Hydrothermal Method & 91 & 3 & {$[16]$} \\
\hline Mn-doped $\mathrm{CeO}_{2}$ & SILAR & 690 & 10 & This work \\
\hline
\end{tabular}

enough time to diffuse through the inner active sites of the electrode while at lower scan rates an increase in specific capacitance was observed due to larger lengths of time permitting better diffusion and intercalation of the ions within the active and interlayer sites. This is in agreement with the report of Nagamuthu et al. [40] and others as shown in Table 4. Most of the Mn doped $\mathrm{CeO}_{2}$ seen in the literature are not used for supercapacitive application. As evidenced from Table 4, the value we obtained is higher than what previous authors obtained using graphene or reduced graphene oxide to form a composite with $\mathrm{CeO}_{2}$.

Fig. 7 is the plot of specific capacitance at different scan rate. It can be seen that the increase in scan rate causes a drastic decrease in specific capacitance.Mn-doped $\mathrm{CeO}_{2}$ films have shown higher specific capacitance than undoped film, this could be as result of its large surface area and porous structure.This is fairly in agreement with the reports of Maheswari et al. [41].

\subsubsection{Galvanostatic charge-discharge (GCD)}

Fig. 8 shows the galvanostatic charge-discharge curves of undoped and $\mathrm{Mn}$-doped $\mathrm{CeO}_{2}$ samples plotted as a potential-time graph at different current densities in $0.1 \mathrm{M}$ aqueous $\mathrm{KOH}$ electrolytes. From the discharge curve as shown in Fig. 8, we observed the following: (i) a linear variation of potential-time plot which is due to charge separation at the electrode-electrolyte interface; and (ii) a deviation in slope which is a result of the redox reaction between electrolyte and electrodes.

At different applied current densities, the specific capacitance could be derived from the voltage-time measurements plot using Eq. (4):

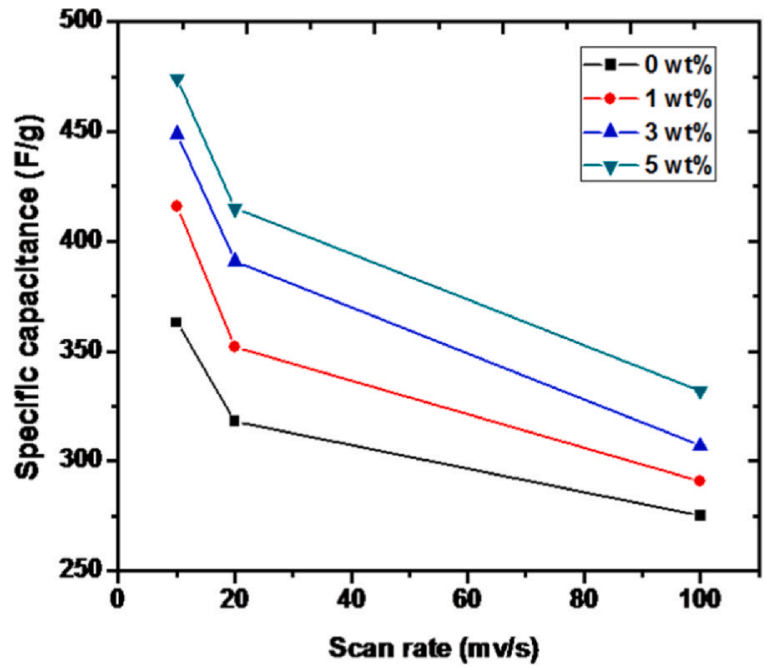

Fig. 7. The specific capacitance of $\mathrm{CeO}_{2}$ and $\mathrm{Mn}$-doped $\mathrm{CeO}_{2}$ films at different scan rates for various $\mathrm{Mn}$ wt\%.

$C_{s}=\frac{I \Delta t}{m \Delta V}$

where $\triangle \mathrm{v}(v)=$ the potential, $m(g)=$ the mass of the deposit and $I \quad(A)=$ the discharge current for the applied time duration $\triangle t(s)$. From Fig. 8, the evaluated values of specific capacitances for $\mathrm{CeO}_{2}$ and $\mathrm{Mn}$-doped $\mathrm{CeO}_{2}$ films at various $\mathrm{Mn} \mathrm{wt} \%(0,1,3$ and $5 \mathrm{wt} \%)$ and different current densities of 2,3 and $4 \mathrm{~mA} \mathrm{~cm}^{-2}$, were found to be 

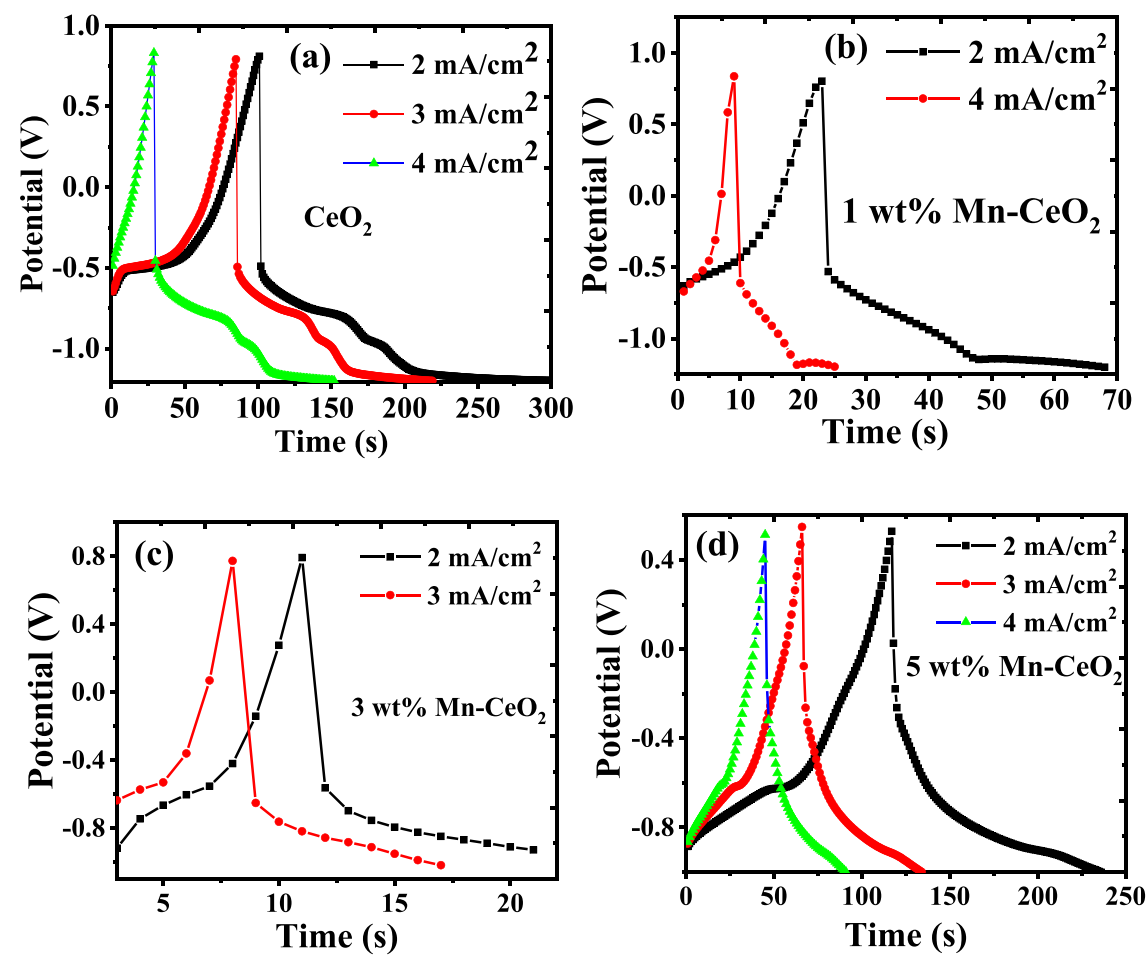

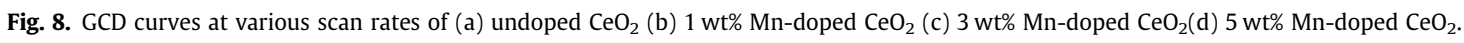

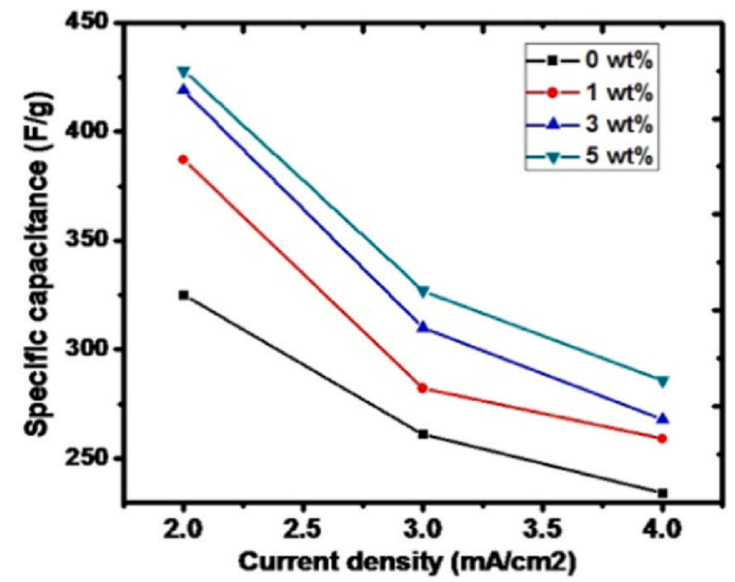

Fig. 9. The specific capacitance against current density of undoped and Mn-doped $\mathrm{CeO}_{2}$ thin films for various $\mathrm{Mn}$ wt\% (1, 3 and 5 respectively).

$325-234,387-259,419-268$ and $428-286 \mathrm{Fg}^{-1}$ for $0,1,3 \& 5 \mathrm{wt} \%$ respectively. The specific capacitance value of undoped $\mathrm{CeO}_{2}$ is quite similar with the report of Maheswari et al. [41]. Due to the increase in surface area, the specific capacitance increases with the increase in the dopant concentration. However, increase in the current density causes lower specific capacitance value in GCD measurements (Fig. 9). Irrespective of how well a device is, the ohmic effect on the polarization due to higher current densities must not be neglected. This is strongly in agreement with the report of Chen et al. [42] and Vijayakumar et al. [43].

\subsubsection{Electrochemical impedance spectroscopy}

The impedance characteristics of undoped and $\mathrm{Mn}$-doped $\mathrm{CeO}_{2}$ electrode were evaluated with electrochemical impedance measurement within the frequency range of $100 \mathrm{KHz}-100 \mathrm{mHz}$ at potential amplitude of $+2.0 \mathrm{~V}$. The Nyquist plots of undoped and Mndoped $\mathrm{CeO}_{2}$ have a semicircular arc at the high frequency region which demonstrates the better capacitive performance of the electrodes as shown in Fig. 10. Insets of Fig. 10 shows the equivalent circuit used to model the electrochemical behaviour of $\mathrm{CeO}_{2}$ electrode and $\mathrm{Mn}$-doped $\mathrm{CeO}_{2}$.

The characteristic equivalent electrical circuits have the basic components such as charge-transfer resistance $\left(R_{\mathrm{ct}}\right)$, ohmic resistance $\left(R_{\mathrm{s}}\right)$, Warburg resistance $(W)$ and capacitor $(C)$ [44]. The charge transfer resistance depicts the resistance involving the electrokinetics exchange between tetravalent cerium and divalent manganese ions i.e. $\mathrm{C} e^{4+}+\mathrm{Mn}^{2+} \rightleftharpoons \mathrm{Mn}^{4+}+\mathrm{Ce}^{2+}$ as well as the resistance to charge movement at the electrode-electrolyte interface. The Warburg resistance in this case corresponds to the diffusion of ionic species in the bulk electrolytic solution whereas the impedance of the bulk $\mathrm{KOH}$ solution is regarded as the ohmic resistance. As observed from Fig. 10, in particular undoped, 1 and 5 wt\% Mn doped $\mathrm{CeO}_{2}$, the Nyquist plot shows a near diagonal at mid to low frequency region, indicating the presence of the Warburg resistance. The diffusion of these ionic species is however known to be slow at high frequency as they do not travel far, thus reducing the Warburg resistance. At low frequency, the diffusion is faster and they travel far; this positively influences the Warburg resistance. For the representative samples, the Warburg resistance is observed to increase/decrease at low/high frequency, again confirming the feature pointed out previously.

The values of charge transfer resistance derived from the experimental results using the equivalent circuit model of undoped and $\mathrm{Mn}$ doped $\mathrm{CeO}_{2}$ were observed to be $6.87,9.21,12.96$ and $18.95 \Omega$ for undoped and $1 \mathrm{wt} \%, 3 \mathrm{wt} \%$ and $5 \mathrm{wt} \%$ for $\mathrm{Mn}$-doped $\mathrm{CeO}_{2}$ respectively. It shows that the charge transfer resistance increases with doping, however other structural factors such as the surface area, porosity, lattice defects which improved in the doped samples enhanced the overall specific capacitance obtained from the doped $\mathrm{CeO}_{2}$. 

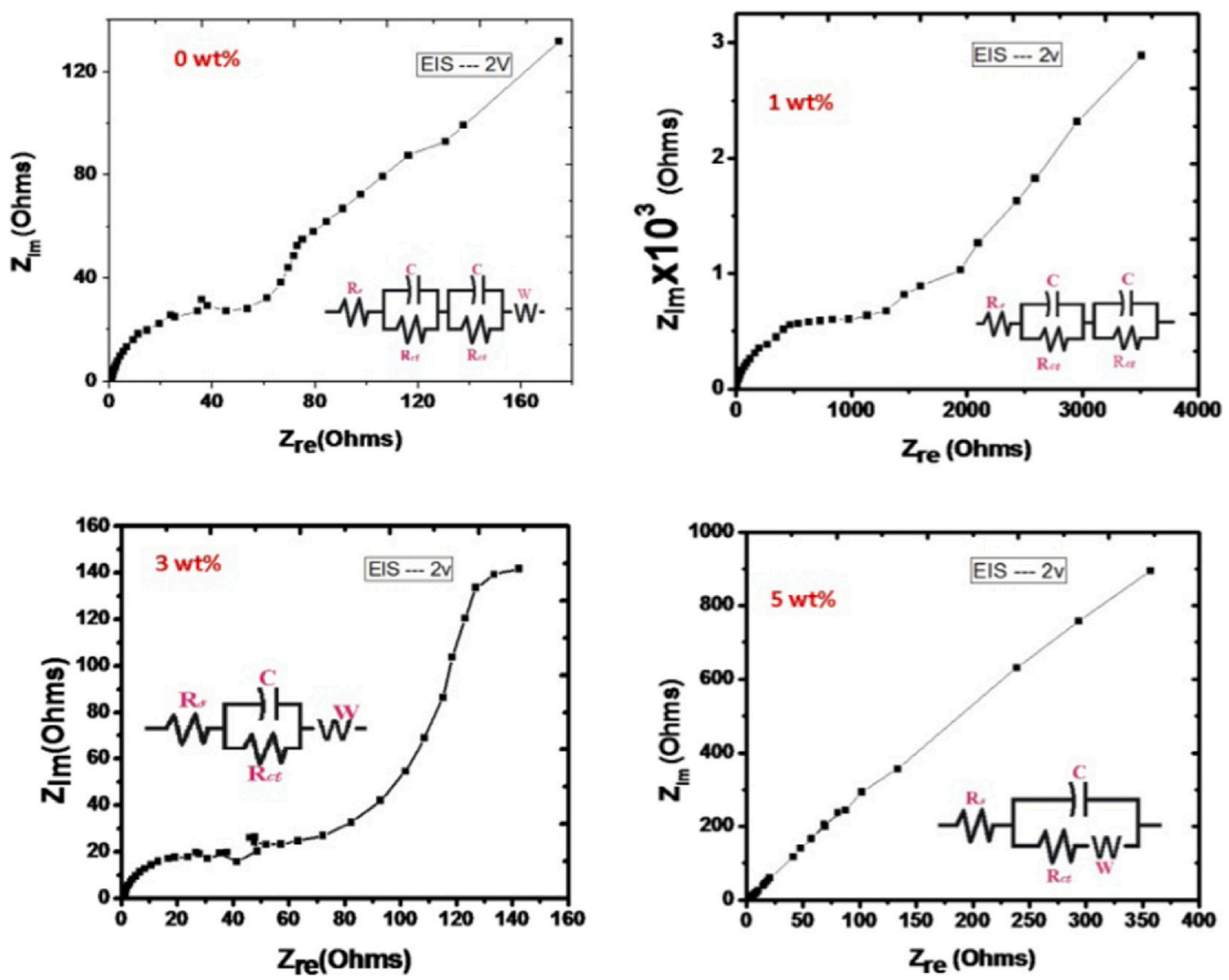

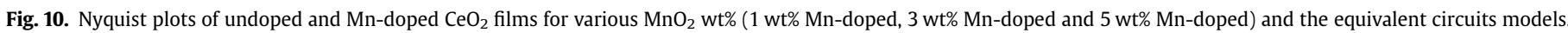

\section{Conclusion}

In summary, undoped and $\mathrm{Mn}$-doped $\mathrm{CeO}_{2}$ thin films electrode materials were successfully synthesized via SILAR method. XRD results confirmed the presence of tensile strain in the fluorite structure of undoped $\mathrm{CeO}_{2}$ because of its slight difference in the metal radii. The electronic transition was due to impurity transition states within the energy gap culminating to a red shift in the absorption edge of the lattice. The XPS spectrum proves that the manganese oxide exists as $\mathrm{Mn}^{4+}$ while the presence of $\mathrm{Ce}^{3+}$ was not noticed. AFM topographies revealed a porous network of spherically shaped grains that provided active sites for electrochemical redox reaction. This remarkable property alongside others paved way for high specific capacitance of $690 \mathrm{Fg}^{-1}$ for $5 \mathrm{wt} \% \mathrm{Mn}$-doped $\mathrm{CeO}_{2}$ as proved by cyclic voltammetry.

\section{CRediT authorship contribution statement}

Nwachukwu, Iheke Micheal: carried out the laboratory synthsis experiments, Drafted the manuscript. Assumpta Chinwe Nwanya: designed the experiments, carried out the electrochemical test and analysis, reviewed and corrected the manuscript. Rose Osuji: carried out part of the data analysis and also reviewed the manuscript. Fabian I. Ezema: was involved in the experimental design, data analysis as well the manuscript review.

\section{Declaration of Competing Interest}

The authors declare that they have no known competing financial interests or personal relationships that could have appeared to influence the work reported in this paper.

\section{Acknowledgements}

We thank the Royal Society and the African Academy of Science for the award of Future Leaders African Independent Research (FLAIR) fellowship (FLR $\mid$ R1 $\mid 201225$ ) to Dr. A.C. Nwanya. The FLAIR Fellowship Programme is a partnership between the African Academy of Sciences and the Royal Society funded by the United Kingdom (UK) Government's Global Challenges Research Fund.

\section{References}

[1] F. Zhao, Y. Wang, X. Xu, Y. Liu, R. Song, G. Lu, Y. Li, Cobalt hexacyanoferrate nanoparticles as a high-rate and ultra-stable supercapacitor electrode material, ACS Appl. Mater. Interfaces 6 (2014) 11007-11012.

[2] G.P. Wang, L. Zhang, J.J. Zhang, A review of electrode materials for electrochemical supercapacitors, Chem. Soc. Rev. 41 (2012) 797-828.

[3] K. Wang, J. Huang, Z. Wei, J. Phys. Chem. C 114 (2010) 8062-8067.

[4] P. Simon, Y. Gogotsi, Materials for electrochemical capacitors, Nat. Mater. 7 (2008) 845-854.

[5] T. Xue, C.L. Xu, D.D. Zhao, X.H. Li, H.L. Li, Electrodeposition of mesoporous manganese dioxide supercapacitor electrodes through self-assembled triblock copolymer templates, J. Power Sources 164 (2007) 953-958.

[6] J.P. Zheng, P.J. Cygan, T.R. Jow, Hydrous ruthenium oxide as an electrode material for electrochemical capacitors, J. Electrochem. Soc. 142 (1995) 2699-2703.

[7] H. Jiang, T. Zhao, J. Ma, C. Yan, C.Z. Li, Ultrafine manganese dioxide nanowire network for high-performance supercapacitors, Chem. Commun. 47 (2011) 1264-1266.

[8] M. Liu, J. Chang, J. Sun, L. Gao, A facile preparation of NiO/Ni composites as highperformance pseudocapacitor materials, RSC Adv. 3 (2013) 8003-8008.

[9] X.H. Xia, J.P. Tu, Y.J. Mai, X.L. Wang, C.D. Gu, X.B. Zhao, Self-supported hydrothermal synthesized hollow $\mathrm{Co}_{3} \mathrm{O}_{4}$ nanowire arrays with high supercapacitor capacitance, J. Mater. Chem. 21 (2011) 9319-9325.

[10] R.S. Kalubarme, Y.H. Kim, C.J. Park, One step hydrothermal synthesis of a carbon nanotube/cerium oxide nanocomposite and its electrochemical properties, Nanotechnology 24 (2013) 365401-365408.

[11] Y. Wang, C. Xian Guo, J. Liu, T. Chen, H. Yang, Li.C. Ming, $\mathrm{CeO}_{2}$ nanoparticles graphene nanocomposite-based high performance supercapacitor, Dalton Trans. 40 (2011) 6388-6391. 
[12] T. Saravanan, M. Shanmugam, P. Anandan, M. Azhagurajan, K. Pazhanivel, M. Arivanandhan, Y. Hayakawa, R. Jayavel, Facile synthesis of graphene- $\mathrm{CeO}_{2}$ nanocomposites with enhanced electrochemical properties for supercapacitors, Dalton Trans. 44 (2015) 9901-9908.

[13] T. Li, H. Liu, A simple synthesis method of nanocrystals $\mathrm{CeO}_{2}$ modified rGO composites as electrode materials for supercapacitors with long time cycling stability, Powder Technol. 327 (2018) 275-281.

[14] J. Mazloom, F.E. Ghodsi, F.Z. Tepehan, G.G. Tepehan, I. Turhan, Enhanced lithium electrochemical performance and optical properties of $\mathrm{CeO}_{2}-\mathrm{SnO}_{2}$ nanocomposite thin films by transition metal (TM: Ni, Mn, and Co) doping, J. Sol-Gel Sci. Technol. 86 (2018) 51-62.

[15] B. Ramulu, G. Nagaraju, S.C. Sekhar, J.S. Yu, Highly porous CNTs knotted cerium oxide hollow tubes with exalted energy storage performance for hybrid supercapacitors, J. Alloy. Compd. 819 (2020) 152942.

[16] S. Britto, V. Ramasamy, P. Murugesan, B. Neppolian, T. Kavinkumar, Graphene based ceria nanocomposite synthesized by hydrothermal method for enhanced supercapacitor performance, Diam. Relat. Mater. 105 (2020) 107808.

[17] G. Hua, L. Zhang, G. Fei, M. Fang, Enhanced catalytic activity induced by defects in mesoporous ceria nanotubes, J. Mater. Chem. 22 (2012) 6851-6855.

[18] L. Cui, J. Cui, H. Zheng, Y. Wang, Y. Qin, X. Shu, J. Liu, Y. Zhang, Y. Wu, J.Power Sources 361 (2017) 310-317.

[19] N. Maheswari, G. Muralidharan, Hexagonal $\mathrm{CeO}_{2}$ nanostructures: an efficient electrode material for supercapacitors, Dalton Trans. 45 (2016) 14352-14362.

[20] Y. Lü, G. Shao, B. Zhao, L. Zhang, J. Wuhan Univ. Technol. Mater. Sci. Ed. 26 (2011) 33-37.

[21] N. Padmanathan, S. Selladurai, Shape controlled synthesis of $\mathrm{CeO}_{2}$ nanostructures for high performance supercapacitor electrodes, RSC Adv. 4 (2014) 6527-6534.

[22] Lee C.E., Choi S.H., Kim H.Y., Lee S.S., Kim SK., An K.-S. , Ceramics International, 2021, In Press, Corrected Proof.

[23] J. Puišo, S. Tamulevicius, G. Laukaitis, S. Lindroos, M. Leskelä, V. Snitka, Thin Solid Films 457 (2002) 403-404.

[24] F. Abbas, T. Jan, J. Iqbal, I. Ahmad, M.S.H. Naqvi, M. Malik, Facile synthesis of ferromagnetic $\mathrm{Ni}$ doped $\mathrm{CeO}_{2}$ nanoparticles with enhanced anticancer activity, Appl. Surf. Sci. 357 (2015) 931-936.

[25] F.A. Al-Agel, E. Al-Arfaj, A.A. Al-Ghamdi, Y. Losovyj, L.M. Bronstein, W.E. Mahmoud, A novel recipe to improve the magnetic properties of Mn doped $\mathrm{CeO}_{2}$ as a room temperature ferromagnetic diluted metal oxide, J. Magn. Magn. Mater. 360 (2014) 73-79.

[26] J.M.A. Almeida, P.E.C. Santos, L.P. Cardoso, C.T. Meneses, A simple method to obtain $\mathrm{Fe}$-doped $\mathrm{CeO}_{2}$ nanocrystals at room temperature, J. Magn. Magn. Mater. 327 (2013) 185-188.

[27] G.K. Williamson, W.H. Hall, X-ray line broadening from filed aluminium and wolfram, Acta Metall. 1 (1953) 22-31.

[28] E. Eric, C. Patrice, P. Danielle, A. St'ephane, F. Gilles, Ce 3d XPS investigation of cerium oxides and mixed cerium oxide (CexTiyOz), Surf. Interface Anal. 40 (2008) 264-267.
[29] Z. Wang, Z. Quan, J. Lin, Remarkable changes in the optical properties of $\mathrm{CeO}(2)$ nanocrystals induced by lanthanide ions doping, Inorg. Chem. 46 (13) (2007) 5237-5242.

[30] T. Masui, K. Fujiwara, K. Machida, G. Adachi, T. Sakata, H. Mori, Characterization of cerium(IV) oxide ultrafine particles prepared using reversed micelles, Chem. Mater. 9 (10) (1997) 2197-2204.

[31] L. Yin, Y. Wang, G. Pang, Y. Koltypin, A. Gedanken, Sonochemical synthesis of cerium oxide nanoparticles-effect of additives and quantum size effect, J. Colloid Interface Sci. 246 (1) (2002) 78-84.

[32] S. Maensiri, C. Masingboon, P. Laokul, W. Jareonboon, V. Promarak, P.L. Anderson, S. Seraphin, Egg white synthesis and photoluminescence of platelike clusters of $\mathrm{CeO}_{2}$ nanoparticles, Cryst. Growth Des. 7 (5) (2007) 950-955.

[33] C.H. Xia, C.G. Hu, P. Chen, B.Y. Wan, X.S. He, Y.H. Tian, Magnetic properties and photoabsorption of the Mn-doped $\mathrm{CeO}_{2}$ nanorods, Mater. Res. Bull. 45 (2010) 794-798.

[34] A. Thurber, K.M. Reddy, V. Shutthanandan, M.H. Engelhard, C. Wang, J. Hays, et al., Phys. Rev. B 76 (2007) 165206-165213.

[35] A. Corma, P. Atienzar, H. Garc, J.Y. Chane-Ching, Hierarchically mesostructured doped $\mathrm{CeO}_{2}$ with potential for solar-cell use, Nat. Mater. 3 (2004) 394-397.

[36] D.P. Dubal, G.S. Gund, R. Holze, H.S. Jadhav, C.D. Lokhande, C. Park, Surfactantassisted morphological tuning of hierarchical $\mathrm{CuO}$ thin films for electrochemical supercapacitors, Dalton Trans. 42 (2013) 6459-6467.

[37] A.C. Nwanya, C. Awada, D. Obi, K. Raju, K.I. Ozoemena, R.U. Osuji, A. Ruediger, M. Maaza, F. Rosei, F.I. Ezema, Nanoporous copper-cobalt mixed oxide nanorod bundles as high performance pseudocapacitive electrodes, J. Electroanal. Chem. 787 (2017) 24-35.

[38] A.C. Nwanya, D. Obi, R.U. Osuji, R. Bucher, M. Maaza, F.I. Ezema, Simple chemical route for nanorod-like cobalt oxide films for electrochemical energy storage applications, J. Solid State Electrochem. 21 (2017) (2017) 2567-2576.

[39] I.C. Amaechi, A.C. Nwanya, D. Obi, C. Sebastine, S.C. Ezugwu, A.E. Udounwa, A.B.C. Ekwealor, R.U. Osuji, M. Maaza, F.I. Ezema, Structural characterization and electrochemical properties of cerium-vanadium ( $\mathrm{Ce}-\mathrm{V})$ mixed oxide films synthesized by chemical route, Ceram. Int. 42 (2016) (2016) 3518-3524.

[40] S. Nagamuthu, S. Vijayakumar, G. Muralidharan, Synthesis of $\mathrm{Mn}_{3} \mathrm{O}_{4}$ /amorphous carbon nanoparticles as electrode material for high performance supercapacitor applications, Energy Fuels 27 (2013) 3508-3515.

[41] N. Maheswari, G. Muralidharan, Int. J. ChemTech Res. 7 (2015) 1185-1190.

[42] Y.C. Chen, Y.K. Hsu, Y.G. Lin, Y.K. Lin, Y.Y. Horng, L.C. Chen, K.H. Chen, Highly flexible supercapacitors with manganese oxide nanosheet/carbon cloth electrode, Electrochim. Acta 56 (2011) 7124-7130.

[43] S. Vijayakumar, S. Nagamuthu, G. Muralidharan, Porous NiO/C nanocomposites as electrode material for electrochemical supercapacitors, ACS Sustain. Chem. Eng. 1 (2013) 1110-1118.

[44] X. Li, J. Rong, B. Wei, Electrochemical behavior of single-walled carbon nanotube supercapacitors under compressive stress, ACS Nano 4 (2010) 6039-6049. 